\title{
Imbalanced secretion of IL-1 $\beta$ and IL-1RA in Chlamydia pneumoniae- infected mononuclear cells from COPD patients
}

\author{
J. Rupp*, H. Kothe\# ${ }^{\#}$ A. Mueller ${ }^{\Uparrow}$, M. Maass*, K. Dalhoff ${ }^{\#}$
}

Imbalanced secretion of $I L-1 \beta$ and $I L-1 R A$ in Chlamydia pneumoniae-infected mononuclear cells from COPD patients. J. Rupp, H. Kothe, A. Mueller, M. Maass, K. Dalhoff. (C) ERS Journals Ltd 2003.

ABSTRACT: Balanced secretion of pro- and anti-inflammatory cytokines is essential in limiting pulmonary inflammation in respiratory infections. It was hypothesised that, in acute infection with Chlamydia pneumoniae, mononuclear cells from chronic obstructive pulmonary disease (COPD) patients lack the opportunity to compensate for the inflammatory immune response by secreting adequate amounts of anti-inflammatory cytokines.

Alveolar macrophages (AMs) and peripheral blood mononuclear cells (PBMCs) from eight COPD patients and eight healthy controls were infected with $C$. pneumoniae in order to determine interleukin (IL)-1ß, IL-1 receptor antagonist (IL-1RA) and IL-8 expression and messenger ribonucleic acid levels.

Secretion of IL-1 $\beta$ was significantly enhanced in AMs (six-fold) and PBMCs (four-fold) from COPD patients after infection with $C$. pneumoniae. Compared to the control group, release of its anti-inflammatory counterpart IL-1RA was diminished in COPD patients, resulting in a significantly higher IL-1ß/IL-1RA ratio in C. pneumoniae-infected AMs and PBMCs from COPD patients.

Mononuclear cells from chronic obstructive pulmonary disease patients have less capacity for balancing the pro-inflammatory immune response caused by Chlamydia pneumoniae infection than those from healthy controls. These findings suggest that, during acute exacerbation with intracellular pathogens, chronic obstructive pulmonary disease patients are predisposed to inflammatory changes in the lungs.

Eur Respir J 2003; 22: 274-279.
*Institute of Medical Microbiology and Hygiene, and Depts of "Medicine III and Rheumatology, University of Lübeck, Lübeck, Germany.

Correspondence: J. Rupp

Institute of Medical Microbiology and Hygiene University of Lübeck

Ratzeburger Allee 160

23538 Lübeck

Germany

Fax: 494515002808

E-mail: jan.rupp@hygiene.ukl.mu-luebeck.de

Keywords: Anti-inflammation

Chlamydia pneumoniae

chronic obstructive pulmonary disease

Received: January 212003

Accepted after revision: March 132003
Chronic obstructive pulmonary disease (COPD) is the fourth leading cause of death in industrialised countries. The precise role of bacterial infection in the pathogenesis of COPD is the subject of ongoing controversy. Approximately one-half of acute exacerbations are caused by bacteria. Besides Streptococcus pneumoniae, Haemophilus influenzae and Moraxella catarrhalis, the obligate intracellular bacterium Chlamydia pneumoniae is associated with $5-10 \%$ of acute exacerbations in COPD patients [1, 2]. C. pneumoniae has become established as a cause of acute episodes of upper and lower respiratory tract infection, whereas its association with persistent inflammation in COPD is less certain [3]. The evidence of serological studies correlating C. pneumoniaespecific immunoglobulin (Ig)G and IgM levels to acute exacerbations in COPD patients is limited due to the high incidence of IgG-seropositivity in adults [4]. Nevertheless, C. pneumoniae $\mathrm{IgA}$ is found more frequently and in higher concentrations in COPD patients with acute exacerbation than in disease-free controls [5].

Following recognition of bacterial pathogens, generation of inflammation in the respiratory tract involves the coordinated expression of pro- and anti-inflammatory cytokines. Proinflammatory cytokines such as interleukin (IL)-1 $\beta$ and tumour necrosis factor (TNF)- $\alpha$ are secreted predominantly by alveolar macrophages (AMs), which represent the first line of defence in the host response against pulmonary pathogens [6], and are known to be potent triggers for an effective immune response [7]. Apart from the beneficial effects of IL-1 $\beta$ and TNF- $\alpha$ in promoting inflammatory cell accumulation and stimulating the antimicrobial capacity of neutrophils [8], an imbalance between pro- and anti-inflammatory cytokines in the pulmonary compartment might contribute to airway wall remodelling and fibrosis of the small airways. The significance of the relationship between IL- $1 \beta, \mathrm{TNF}-\alpha$ and their anti-inflammatory counterparts IL-1 receptor antagonist (IL-1RA) and soluble TNF receptor I has been well established in lung diseases such as sarcoidosis [9] and pulmonary tuberculosis [10]. To date, data concerning the effect of bacterial pathogens on the balance between pro- and anti-inflammatory cytokines in COPD patients are lacking. In order to differentiate between local and systemic abnormalities in the host response against $C$. pneumoniae infection, release of IL-1 $\beta$ and IL-1RA from AMs and peripheral blood mononuclear cells (PBMCs) from COPD patients and healthy volunteers was evaluated.

\section{Methods}

\section{Subjects}

For in vitro experiments, PBMCs and AMs were isolated from COPD patients who underwent fibreoptic bronchoscopy for diagnostic evaluation of peripheral solitary pulmonary nodules. All COPD patients and controls (healthy male volunteers) were without clinical and laboratory signs of acute infection at the time of bronchoscopic examination. 
Diagnosis of COPD was made according to American Thoracic Society guidelines [11]. Spirometry (BodyScope; Ganshorn Medizin, Niederlauer, Germany) was performed in the sitting position, and forced expiratory volume in one second (FEV1) and forced vital capacity measured. At the same time point, venous blood from patients and volunteers was drawn from a cubital vein into four 10-mL tubes containing ethylene diamine tetra-acetic acid (Sarstedt, Nümbrecht, Germany).

The protocol was approved by the Ethical Committee of the Medical University of Lübeck (01-084). All volunteers gave written informed consent.

\section{$B A L$}

Bronchoalveolar lavage (BAL) was performed as described previously [12]. In brief, a fibreoptic bronchoscope was wedged into the right middle lobe. A total of $200 \mathrm{~mL}$ phosphatebuffered isotonic saline ( $\left.\mathrm{pH} 7.4,25^{\circ} \mathrm{C}\right)$ was instilled sequentially and gently aspirated. The amount of returned fluid was $>60 \%$ of the total infused volume in all patients and volunteers. Aliquots were retained for further microbiological testing. The chilled BAL fluid (BALF) was strained through a single layer of coarse gauze and centrifuged for $15 \mathrm{~min}$ at $400 \times g$ at $4{ }^{\circ} \mathrm{C}$ to recover cells. After washing steps with saline, the cell pellet was resuspended in serum-free Roswell Park Memorial Institute (RPMI) 1640 medium (Sigma, Taufkirchen, Germany) and adjusted to an AM density of $1 \times 10^{6}$ cells $\cdot \mathrm{mL}^{-1}$.

\section{C. pneumoniae nested PCR using BAL fluid}

BALF was analysed for genomic C. pneumoniae deoxyribonucleic acid (DNA) using a nested polymerase chain reaction (PCR) protocol [13]. Briefly, DNA was purified from BALF via proteinase $\mathrm{K}$ digestion and cetyltrimethylammonium bromide treatment. Nested PCR was then performed using the species-specific HL-1/HR-1 primer pair and the nested primer pair IN-1/2 that yields a product of 128 base pairs. Nonradioactive DNA hybridisation was performed using oligonucleotide HM-1 3'-labelled with digoxigenin-deoxyuridine triphosphate (Boehringer Mannheim, Mannheim, Germany) as the probe.

\section{Isolation of human PBMCs}

Isolation of PBMCs was performed by density centrifugation of blood diluted $1: 2$ in pyrogen-free saline over Histopaque (Sigma). PBMCs were washed twice in saline, resuspended in RPMI 1640 medium and adjusted to $1 \times 10^{6}$ cells $\cdot \mathrm{mL}^{-1}$ as described for AMs.

\section{Culture of $\mathrm{C}$. pneumoniae}

The pulmonary $C$. pneumoniae strain CWL-029 (American Type Culture Collection (ATCC) VR-1310) was grown on HEp-2 monolayers as described previously [14]. Briefly, immortalised laryngeal epithelial cells (HEp-2, ATCC CLL 23) were grown in tissue culture plates in Eagle minimal essential medium (Sigma) containing 10\% foetal calf serum (Biochrom KG, Berlin, Germany), L-glutamine (Invitrogen, Leek, the Netherlands; $2 \mathrm{mM}$ ), nonessential amino acids (Invitrogen), gentamicin (Sigma; $10 \mathrm{mg} \cdot \mathrm{L}^{-1}$ ), vancomycin $\left(\right.$ Sigma; $\left.50 \mathrm{mg} \cdot \mathrm{L}^{-1}\right)$ and amphotericin B (Sigma; $\left.2 \mathrm{mg} \cdot \mathrm{L}^{-1}\right)$.
Confluent monolayers were infected with $C$. pneumoniae and growth medium was replaced by an antibiotic-free medium.

\section{Infection of $A M s$ and PBMCs with C. pneumoniae}

AMs and PBMCs were seeded into six-well plates (Invitrogen) for determination of messenger ribonucleic acid (mRNA) expression (at 4, 12, 24 and $48 \mathrm{~h}$ ); cover slips were inserted into the plates to allow mononuclear cell adherence and facilitate staining procedures. After $2 \mathrm{~h}$, the nonadherent population was removed and fresh medium containing C. pneumoniae $\left(50 \%\right.$ tissue culture infective dose $=1 \times 10^{-2.7}$ dilution $/ 1 \times 10^{6}$ inclusion forming units $\cdot \mathrm{mL}^{-1}$ ) added. Supernatants were used for cytokine measurements and stored at $-70^{\circ} \mathrm{C}$.

\section{Real-time PCR}

Total ribonucleic acid (RNA) from AMs and PBMCs from COPD patients was isolated using a NucleoSpin RNA II kit (Macherey-Nagel, Düren, Germany). Extracted RNA was reverse transcribed to give complementary DNA using random primers and reverse transcriptase according to the manufacturer's protocol (First-Strand PCR kit; Roche, Mannheim, Germany). PCR amplification and quantification was performed using the LightCycler Detection System (Roche Molecular Biochemicals, Mannheim, Germany). Primers were designed using computer software containing minimal internal structure and having compatible melting temperatures. The sequences of the primers are as follows: forward glyceraldehyde-3-phosphate dehydrogenase (GAPDH): 5'TCTGCCCCCTCTGCTGATGCCCCC-3'; reverse GAPDH: 5' CCATCACGCCACAGTTTCCCGGAG-3'; forward IL-1 $\beta$ : 5'-CTGATGGCCCTAAACAGATGAAG-3'; reverse IL-1 $\beta$ : 5'-GGTCGGAGATTCGTAGCAGCTGGAT-3'; forward IL1RA: 5'-GGAATCCATGGAGGGAAGAT-3'; and reverse IL-1RA: 5'-CCTTCGTCAGGCATATTGGT-3'. The PCR product was monitored in real-time by measuring the increase in fluorescence caused by the binding of SYBR Green I Dye (Roche Molecular Biochemicals) to double-stranded DNA.

\section{Determination of cytokine concentrations}

Concentrations of IL-1 $\beta$, IL-1RA and IL-8 were determined in cell supernatants by means of enzyme-linked immunosorbent assays with detection limits of 3.9, 31.2 and $16 \mathrm{pg} \cdot \mathrm{mL}^{-1}$, respectively (Biosource International, Camarillo, CA, USA; Bender MedSystems, Vienna, Austria; and R\&D Systems, Minneapolis, MN, USA).

Table 1.-Characteristics of study subjects

COPD patients Healthy controls

\begin{tabular}{|c|c|c|}
\hline Subjects $n$ & 8 & 8 \\
\hline Age yrs & $57.3 \pm 12.1$ & $28.0 \pm 6.1$ \\
\hline Current smokers $\mathrm{n}$ & 8 & 8 \\
\hline FEV1 L & $2.5 \pm 1.1$ & $4.5 \pm 0.7$ \\
\hline$\%$ pred & $73.5 \pm 11.5$ & $91.8 \pm 9.7$ \\
\hline FEV1/FVC \% & $65.9 \pm 18.3$ & $82.4 \pm 6.0$ \\
\hline \multicolumn{3}{|l|}{ Bronchoalveolar lavage fluid } \\
\hline Cell density $10^{7}$ cells $\cdot \mathrm{mL}^{-1}$ & $1.2 \pm 0.7$ & $0.9 \pm 0.5$ \\
\hline Alveolar macrophages \% & $92 \pm 7$ & $95 \pm 4$ \\
\hline PMNs \% & $4 \pm 2$ & $3 \pm 2$ \\
\hline Cell viability \% & $95 \pm 4$ & $97 \pm 3$ \\
\hline
\end{tabular}

Data are presented as mean \pm SD. COPD: chronic obstructive pulmonary disease; FEV1: forced expiratory volume in one second; FVC: forced vital capacity; PMN: polymorphonuclear neutrophils; \% pred: percentage of the predicted value. 


\section{Fluorescence microscopy}

A two-colour fluorescence assay (LIVE/DEAD®) kit; MolecularProbes, Eugene, OR, USA) was used to determine the viability of $C$. pneumoniae and PBMCs over $48 \mathrm{~h}$. Green fluorescence indicated viable cells as the highly membrane permeable dye (Syto 9) labels cells with intact plasma membranes. In contrast, the red fluorescent nucleic acid stain (propidium iodide) labels only cells with disrupted membranes. C. pneumoniae-infected PBMCs and AMs were seeded on to sterile glass coverslips and incubated with both fluorescent dyes (at 1:300 dilution) for $45 \mathrm{~min}$ in darkness. Dye solution was removed, cells were fixed in 1\% paraformaldehyde for $10 \mathrm{~min}$ and stored at $-4^{\circ} \mathrm{C}$. Infection rates were determined using a fluorescein isothiocyanate-conjugated antichlamydial antibody (Dako, Hamburg, Germany).

\section{Statistical analysis}

For statistical analysis, nonparametric tests were used throughout the study. As maximum IL-1 $\beta$ secretion from
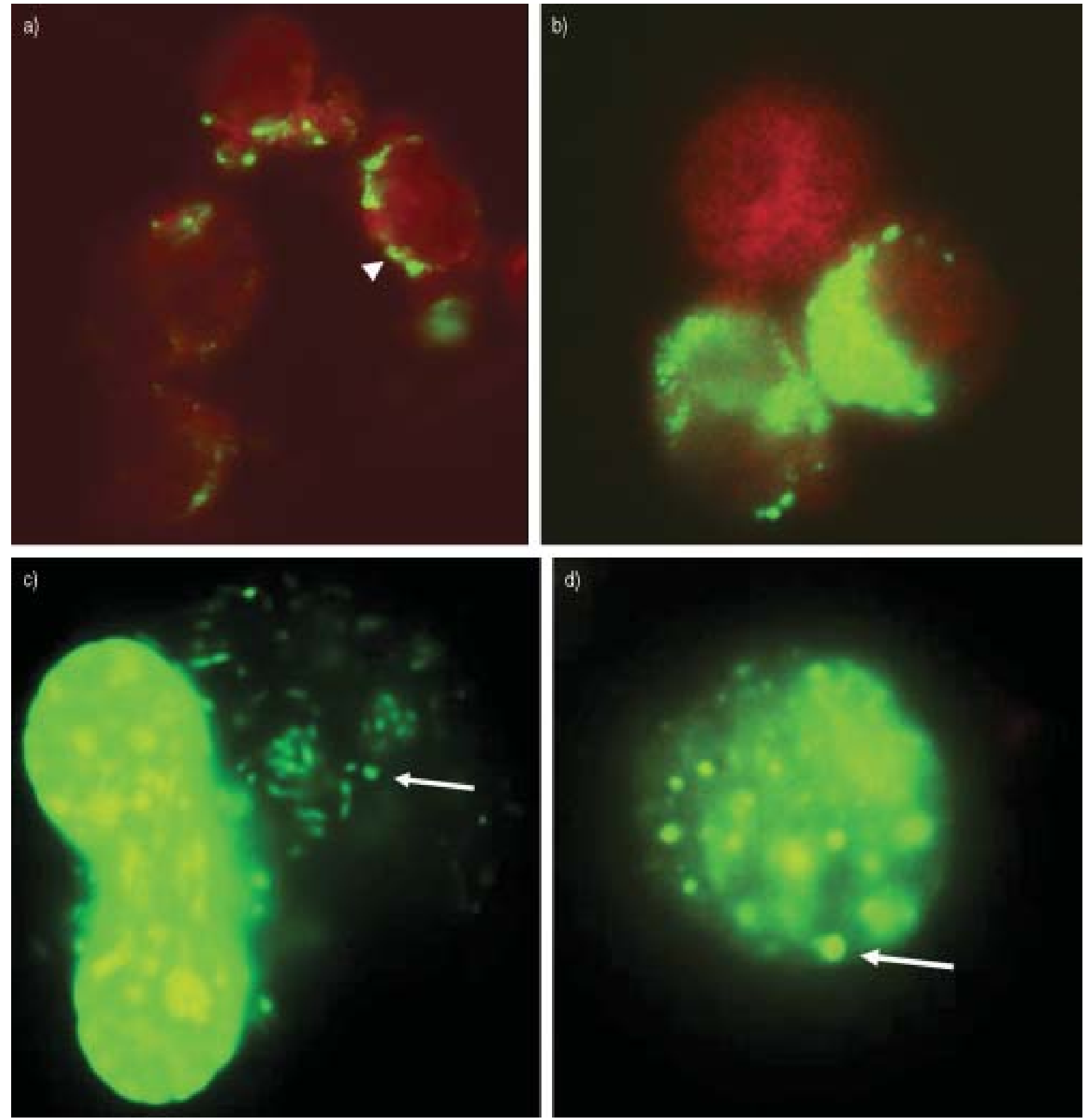

Fig. 1.-Fluorescence microscopy with fluorescein isothiocyanate-conjugated antichlamydial antibody showing the development of intracellular chlamydial infection in peripheral blood mononuclear cells after a) $24 \mathrm{~h}$ and b) $48 \mathrm{~h}$. Increasing viability of Chlamydia pneumoniae was demonstrated in alveolar macrophages after c) $24 \mathrm{~h}$ and d) $48 \mathrm{~h}$ by live/dead staining. Arrows/arrowheads indicate $C$. pneumoniae. 
C. pneumoniae-infected PBMCs was detected after $24 \mathrm{~h}$, this time was appointed for the statistical analysis of samples from the COPD patients and healthy controls (Mann-Whitney U-test). A $\mathrm{p}<0.05$ was considered significant.

\section{Results}

\section{Study subjects}

The clinical characteristics of the subjects are shown in table 1. All COPD patients and volunteers were male current smokers with a cumulative cigarette consumption of $\geqslant 6$ pack-yrs. None of the COPD patients were receiving systemic steroids or antibiotic treatment at the time of the study. No potentially pathogenic microorganisms were isolated from BALF, and PCR was negative for C. pneumoniae in all COPD patients and healthy controls included in the study.

Infection rates and viability of $\mathrm{C}$. pneumoniae-infected AMs and PBMCs

Inclusion-forming bodies of $C$. pneumoniae were observed 24 and $48 \mathrm{~h}$ after infection of AMs and PBMCs (fig. 1a and b), indicating an intracellular infection. In mononuclear cells from COPD patients and healthy volunteers, infection rates ranged from $65 \pm 10 \%$ in $\mathrm{AMs}$ to $73 \pm 8 \%$ in $\mathrm{PBMCs}$ without differences between the two groups. Viable $C$. pneumoniae could be detected in viable AMs (fig. 1c and d) and PBMCs over $48 \mathrm{~h}$ with live/dead staining.

Expression of $I L-1 \beta$ and $I L-1$ receptor antagonist in C. pneumoniae-infected $A M s$ and $P B M C s$ from $C O P D$ patients

In order to evaluate the time course of pro- and antiinflammatory cytokine production in AMs and PBMCs from COPD patients, IL-1 $\beta$ and IL-1RA expression and mRNA levels were determined $4,12,24$ and $48 \mathrm{~h}$ after chlamydial infection in a subgroup of six patients. Levels of IL-1 $\beta$ mRNA were significantly enhanced four-fold $4 \mathrm{~h}$ after infection of AMs and PBMCs with C. pneumoniae. Secretion of IL-1 $\beta$ from AMs reached maximum levels $24 \mathrm{~h}$ after chlamydial infection with continual decrease up to $48 \mathrm{~h}$ (fig. $2 \mathrm{a}$ ). In contrast, infection with $C$. pneumoniae did not result in enhanced levels of IL-1RA mRNA. There was no significant difference in release of IL-1RA from C. pneumoniae-infected and noninfected AMs (fig. 2b) and PBMCs at $24 \mathrm{~h}$.

IL-1 $\beta / I L-1$ receptor antagonist ratio in C. pneumoniaeinfected $A M$ s and PBMCs from COPD patients and healthy volunteers

Infection of AMs and PBMCs from COPD patients with $C$. pneumoniae resulted in increased secretion of IL-1 $\beta$. Compared to healthy controls, the maximum increase was 2.5-fold in AMs and 2.3-fold in PBMCs, starting from similar baseline levels. Strikingly, enhanced release of its antiinflammatory counterpart IL-1RA was absent in preactivated AMs and PBMCs from COPD patients after chlamydial infection (fig. 3). In contrast, mononuclear cells from healthy volunteers possessed the capacity to functionally balance the pro-inflammatory immune response by secreting increased amounts of IL-1RA (106.8 \pm 40.6 versus $69.0 \pm 38.7 \mathrm{ng} \cdot \mathrm{mL}^{-1}$ from AMs and $16.9 \pm 6.0$ versus $5.8 \pm 4.2 \mathrm{ng} \cdot \mathrm{mL}^{-1}$ from PBMCs; $p<0.05$ ) after chlamydial infection.
Taken together, the IL-1 $\beta /$ IL-1RA ratio $(\times 1,000)$ in AMs (and PBMCs) from COPD patients increased significantly from $6.3 \pm 2.9$ to $27.1 \pm 4.1(170.6 \pm 65.2$ to $511.4 \pm 196.5$ in PBMCs) in response to $C$. pneumoniae infection. In the control group, infection of AMs with $C$. pneumoniae did not significantly affect the IL-1 $\beta / \mathrm{IL}-1 \mathrm{RA}$ ratio $(4.6 \pm 2.5$ versus $7.3 \pm 1.2)$, whereas there was a tendency for it to decrease in C. pneumoniae-infected PBMCs (186.6 \pm 92.7 versus $85.4 \pm 20.6)$.

Release of IL-8 from C. pneumoniae-infected AMs from $C O P D$ patients and healthy volunteers

In both groups, infection of AMs with C. pneumoniae resulted in a 4.5 -fold increase in IL-8 secretion. In contrast to other cytokines, basal IL-8 levels in unstimulated AMs from COPD patients were significantly enhanced compared to the control group $\left(283.0 \pm 112.0\right.$ versus $\left.6.5 \pm 2.3 \mathrm{ng} \cdot \mathrm{mL}^{-1} ; \mathrm{p}<0.05\right)$. As the inducibility of IL-8 secretion from AMs was similar in both groups, infection of AMs from COPD patients with C. pneumoniae resulted in significantly enhanced IL-8 levels (1324.4 \pm 498.3 versus $\left.43.9 \pm 14.9 \mathrm{ng} \cdot \mathrm{mL}^{-1} ; \mathrm{p}<0.05\right)$.

\section{Discussion}

Five to ten per cent of acute exacerbations in COPD patients are associated with $C$. pneumoniae infection $[1,2,15]$.
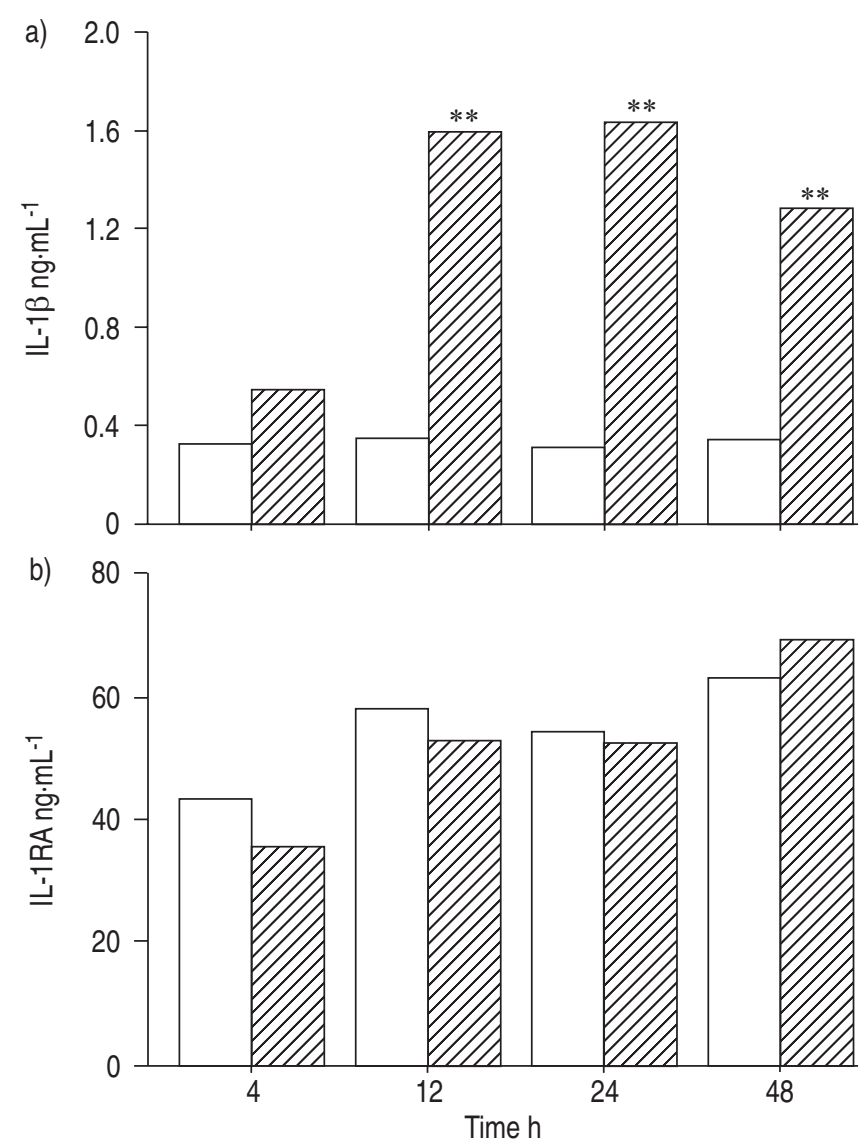

Fig. 2.-Time course of a) interleukin (IL)-1 $\beta$ and b) IL-1 receptor antagonist (IL-1RA) secretion from Chlamydia pneumoniae-infected $(\mathbb{Z})$ and noninfected $(\square)$ alveolar macrophages (AMs) from chronic obstructive pulmonary disease patients $(n=6)$. Within $12 \mathrm{~h}$, secretion of IL-1 $\beta$ was significantly enhanced in infected AMs, whereas release of IL-1RA from AMs remained unaffected by infection over $48 \mathrm{~h}$. **: $\mathrm{p}<0.01$ versus noninfected AMs. 

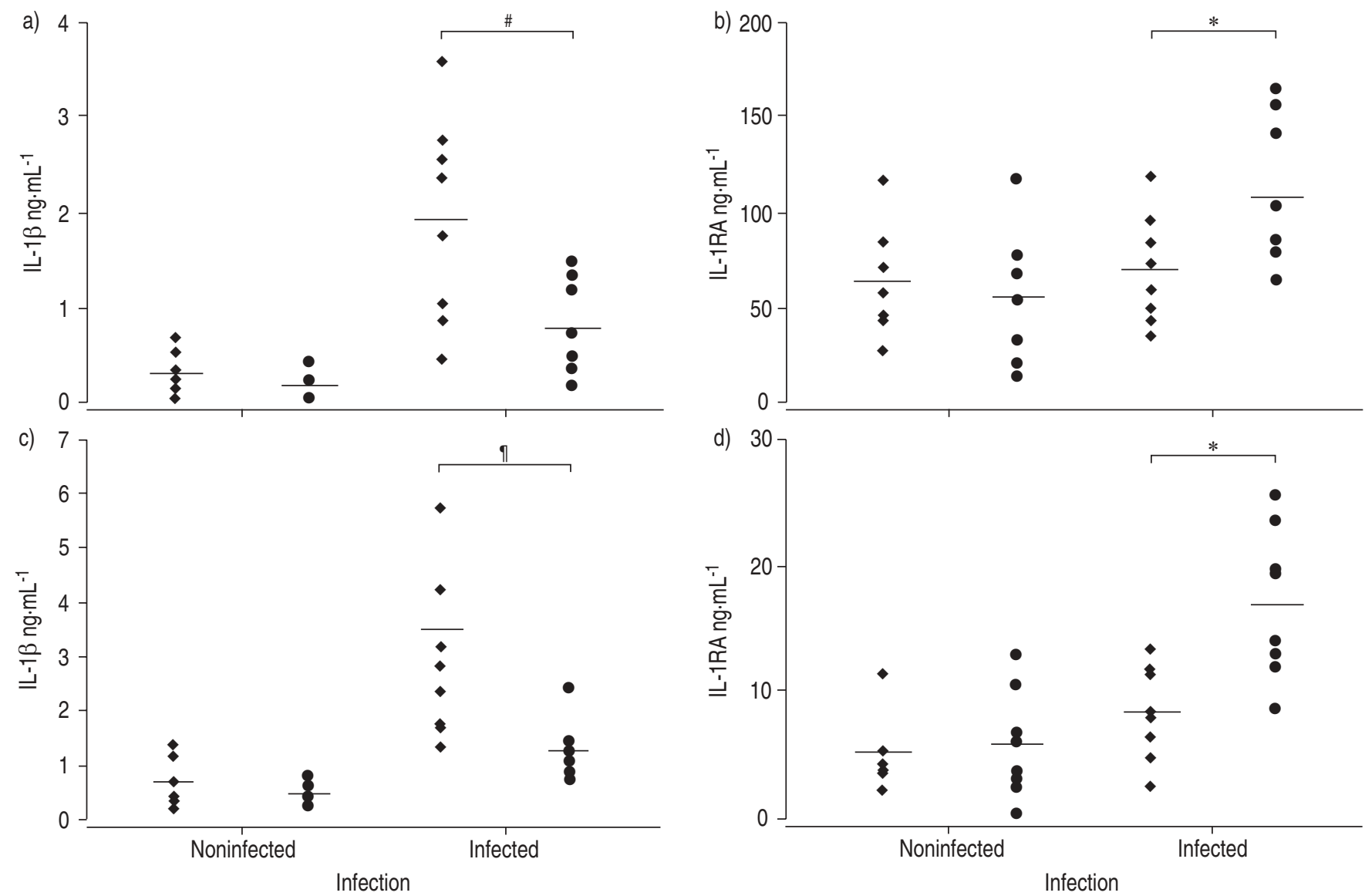

Fig. 3. - Secretion of a, c) interleukin (IL)-1 $\beta$ and b, d) IL-1 receptor antagonist (IL-1RA) from a, b) alveolar macrophages (AMs) and c, d) peripheral blood mononuclear cells (PBMCs) from chronic obstructive pulmonary disease (COPD) patients $(\diamond)$ and healthy controls $(\bullet) 24 \mathrm{~h}$ after infection with Chlamydia pneumoniae. Horizontal bars represent means $(\mathrm{n}=8)$. Infection of AMs and PBMCs from COPD patients resulted in an increased IL-1 //L-1RA ratio compared to healthy volunteers due to enhanced expression of IL-1 $\beta$ but unchanged secretion of IL-1RA. *: $\mathrm{p}<0.05 ;{ }^{\#}: \mathrm{p}=0.016 ;{ }^{\uparrow}: \mathrm{p}=0.009$.

In acute exacerbation of COPD, the pulmonary compartment represents a site of localised inflammation, in which AMs play a pivotal role in the host defence against bacterial pathogens [16]. Initially, C. pneumoniae infects AMs, which results in enhanced secretion of the pro-inflammatory cytokines IL-1 $\beta$ and TNF- $\alpha$ [17]. Besides the beneficial effects of proinflammatory cytokine secretion in infectious diseases, some of their biological activities may contribute to structural tissue damage if an adequate anti-inflammatory immune response is lacking [18].

In the present study, the relationship between release of IL$1 \beta$ and its anti-inflammatory counterpart IL-1RA was investigated in C. pneumoniae-infected AMs and PBMCs in order to assess the role of a balanced immune response to intracellular pathogens in respiratory infections in COPD patients. Infection of AMs and PBMCs from COPD patients with $C$. pneumoniae resulted in a predominant increase in the pro-inflammatory cytokine IL-1 $\beta$ in a dose- and timedependent manner. Interestingly, this increase was significantly more distinct in COPD than in the control group, starting from similar baseline levels.

The pro-inflammatory cytokine secretion pattern of $C$. pneumoniae-infected AMs and PBMCs from healthy persons has been described previously [17, 19], whereas data concerning the release of anti-inflammatory cytokines are lacking.

It is widely accepted that IL-1RA is a successful inhibitor of IL-1 $\beta$ bioactivity in vivo $[20,21]$. The importance of a balanced immune response has been described in detail as regards the regulation of IL-1 $\beta$ and IL-1RA, which competitively block the binding of IL- $1 \alpha$ and IL- $1 \beta$ without inducing a cellular signal of their own [22]. Patients with active pulmonary tuberculosis and large necrotic cavities are characterised by elevated IL-1 $\beta / \mathrm{IL}-1 \mathrm{RA}$ ratios in BALF, giving rise to the assumption that an imbalance in IL-1 $\beta / \mathrm{IL}$ 1RA contributes to severe tissue damage [10]. The present results indicate that AMs and PBMCs from healthy volunteers have a greater capacity to balance IL-1 $\beta$ activity by increased production of IL-1RA. Even though cytokine levels may differ in elderly patients, it seems unlikely that the greater age in this patient group is decisive for the observed mismatch in IL-1 $\beta$ and IL-1RA secretion. Population studies revealed increased production of IL-1RA from blood mononuclear cells in the elderly, whereas IL-1 $\beta$ levels remained unchanged on ageing [23].

PBMCs and AMs have been reported to play an important role in the regulation of the systemic and local inflammatory response by expression of high IL-1RA levels [24]. Joos et. al. [25] showed that polymorphisms in the IL-1 $\beta$ and IL-1RA genes are linked to the rate of decline in lung function in smokers, indicating a genetic predisposition for enhanced susceptibility to lung tissue damage. The absence of adequate IL-1RA secretion in COPD patients may explain the sustained inflammatory responses in acute exacerbations with intracellular pathogens, by interference with IL-1 $\beta$-dependent adhesion molecule expression and IL-8 generation, resulting in enhanced neutrophil recruitment and activation [26]. 
Significantly enhanced IL-8 levels were found in C. pneumoniaeinfected and unstimulated AMs from COPD patients in the present study. Increased sputum levels of IL-8 associated with enhanced neutrophil activation have been previously reported during acute exacerbation in COPD patients [27, 28].

The precise role of exacerbations in patients suffering from chronic obstructive lung disease in tissue destruction and FEV1 decline is still the subject of controversy. LEWIS et al. [29] found, in a population study, that increased blood monocyte counts were related to reduced FEV1, suggesting a central role of monocytes and tissue macrophages in the pathogenesis of COPD. To the present authors' knowledge, the current data are the first demonstrating an imbalance in the release of pro- and anti-inflammatory cytokines from inflammatory cells from COPD patients in response to infection with an intracellular pathogen. The present findings indicate a possible pathophysiological mechanism for perpetuating the inflammatory process in the lungs, since a well balanced anti-inflammatory cytokine response is indispensable for limiting inflammation in the pulmonary compartment. Further studies are needed to evaluate the balance of pro- and anti-inflammatory cytokines in BALF from COPD patients with acute exacerbations with respect to their status regarding acute or persistent $C$. pneumoniae infection, and to clarify whether the higher exacerbation rate in patients with persistent $C$. pneumoniae infection [30] is associated with the in vitro observed cytokine mismatch. In patients with C. pneumoniae DNA-positive pneumonia without underlying pulmonary disease, balanced secretion of IL-1 $\beta$ and IL-1RA was observed in BALF (unpublished data).

Finally, the present study demonstrates that the imbalance in the release of pro- and anti-inflammatory cytokines in response to Chlamydia pneumoniae infection is not limited to the lungs since it can also be detected in infected blood monocytes from chronic obstructive pulmonary disease patients. This finding may suggest that genetic differences in the regulation of the inflammatory response to intracellular pathogens in chronic obstructive pulmonary disease are equally as important as environmental factors, which primarily affect the airways.

\section{References}

1. Sethi S, Murphy TF. Bacterial infection in chronic obstructive pulmonary disease in 2000: a state-of-the-art review. Clin Microbiol Rev 2001; 14: 336-363.

2. Soler N, Torres A, Ewig S, et al. Bronchial microbial patterns in severe exacerbations of chronic obstructive pulmonary disease (COPD) requiring mechanical ventilation. Am J Respir Crit Care Med 1998; 157: 1498-1505.

3. Miyashita N, Niki M, Nakajima M, Kwame H, Matsushima T. Chlamydia pneumoniae infection in patients with diffuse panbronchiolitis and COPD. Chest 1998; 114: 969-971.

4. Beaty CD, Graystone JT, Wang SP, Kuo CC, Reto CS, Martin TR. Chlamydia pneumoniae, strain TWAR, infection in patients with chronic obstructive pulmonary disease. Am Rev Respir Dis 1991; 144: 1408-1410.

5. von Hertzen $\mathrm{L}$, Isoaho $\mathrm{R}$, Leinonen $\mathrm{M}$, et al. Chlamydia pneumoniae antibodies in chronic obstructive pulmonary disease. Int J Epidemiol 1996; 25: 658-664.

6. Shapiro SD. The macrophage in chronic obstructive pulmonary disease. Am J Respir Crit Care Med 1999; 160: S29-S32.

7. Le J, Vilcek J. Tumor necrosis factor- $\alpha$ and interleukin 1 : cytokines with multiple overlapping biological activities. Lab Invest 1987; 56: 234-248.

8. Leff AR, Hamann KJ, Wegner CD. Inflammation and cell-cell interactions in airway hyperresponsiveness. $\mathrm{Am}$ J Physiol Lung Cell Mol Physiol 1991; 260: 189-206.

9. Armstrong L, Foley NM, Millar AB. Inter-relationship between tumor necrosis factor-alpha (TNF- $\alpha$ ) and TNF soluble receptors in pulmonary sarcoidosis. Thorax 1999; 54: 524-530.

10. Tsao TCY, Hong JH, Li LF, Hsieh MJ, Liao SK, Chang KS. Imbalances between tumor necrosis factor- $\alpha$ and its soluble receptor forms, and interleukin-1 $\beta$ and interleukin-1 receptor antagonist in BAL fluid of cavitary pulmonary tuberculosis. Chest 2000; 117: 103-109.

11. Ferguson GT. Recommendations for the management of COPD. Chest 2000; 117: 23S-28S.

12. Reynolds HY. Bronchoalveoalar lavage. Am Rev Respir Dis 1987; 135: 250-263.

13. Maass M, Bartels C, Engel PM, Mamat U, Sievers HH. Endovascular presence of viable Chlamydia pneumoniae is a common phenomenon in coronary artery disease. $J$ Am Coll Cardiol 1998; 31: 827-832.

14. Maass M, Harig U. Evaluation of culture conditions used for isolation of Chlamydia pneumoniae. Am J Clin Pathol 1995; 103: 141-148.

15. Karnak D, Beng-sun S, Beder S, Kayacan O. Chlamydia pneumoniae infection and acute exacerbation of chronic obstructive pulmonary disease (COPD). Respir Med 2001; 95: 811-816.

16. Lohmann-Matthes ML, Steinmüller C, Franke-Ullmann G. Pulmonary macrophages. Eur Respir J 1994; 7: 1678-1689.

17. Redecke V, Dalhoff K, Bohnet S, Braun J, Maass M. Interaction of Chlamydia pneumoniae and human alveolar macrophages and inflammatory response. Am J Respir Cell Mol Biol 1998; 19: 721-727.

18. Dinarello CA. Biologic basis for interleukin-1 in disease. Blood 1996; 87: 2095-2147.

19. Heinemann M, Susa M, Simnacher U, Marre R, Essig A. Growth of Chlamydia pneumoniae induces cytokine production and expression of CD14 in a human monocytic cell line. Infect Immun 1996; 64: 4872-4875.

20. Nicod LP, Galve-De Rochemonteix B, Dayer JM. Modulation of IL-1 receptor antagonist and TNF-soluble receptors produced by alveolar macrophages and blood monocytes. Ann N Y Acad Sci 1994; 725: 323-330.

21. Nicklin MJ, Hughes DE, Barton JL, Ure JM, Duff GW. Arterial inflammation in mice lacking the interleukin 1 receptor antagonist gene. J Exp Med 2000; 191: 303-312.

22. Lennard AC. Interleukin-1 receptor antagonist. Crit Rev Immunol 1995; 15: 77-105.

23. Roubenoff R, Harris TB, Abad LW, Wilson PW, Dallal GE, Dinarello CA. Monocyte cytokine production in an elderly population: effect of age and inflammation. J Gerontol A Biol Sci Med Sci 1998; 53: M20-M26.

24. Moore S, Strieter RM, Rolfe MW, Standiford TJ. Expression and regulation of human alveolar macrophage-derived interleukin-1 receptor antagonist. Am J Respir Cell Mol Biol 1992; 6: 569-575.

25. Joos L, McIntyre L, Ruan J, et al. Association of IL-1 $\beta$ and IL-1 receptor antagonist haplotypes with the rate of decline in lung function in smokers. Thorax 2001; 56: 863-866.

26. Hattar K, Fink L, Fietzner K, et al. Cell density regulates neutrophil IL-8 synthesis: role of IL-1 receptor antagonist and soluble TNF receptors. J Immunol 2001; 166: 6287-6293.

27. Aaron SD, Angel JB, Lunau M, et al. Granulocyte inflammatory markers and airway infection during acute exacerbation of chronic obstructive pulmonary disease. $\mathrm{Am}$ J Respir Crit Care Med 2001; 163: 349-355.

28. Pesci A, Balbi B, Majori M, et al. Inflammatory cells and mediators in bronchial lavage of patients with chronic obstructive pulmonary disease. Eur Respir J 1998; 12: 380-386.

29. Lewis SA, Pavord ID, Stringer JR, Knox AJ, Weiss ST, Britton JR. The relation between peripheral blood leukocyte counts and respiratory symptoms, atopy, lung function, and airway responsiveness in adults. Chest 2001; 119: 105-114.

30. Blasi F, Damato S, Cosentini R, et al., and the Chlamydia InterAction with COPD (CIAC) Study Group. Chlamydia pneumoniae and chronic bronchitis: association with severity and bacterial clearance following treatment. Thorax 2002; 57: 672-676. 